\title{
Fine needle Aspiration Cytology: Diagnostic Efficacy in Malignant Breast Lesions
}

\author{
Cherukattil Hazeena ${ }^{1 \%}$ and Saldanha Prema ${ }^{2}$ \\ ${ }^{1}$ Government Medical College, Kozhikode, Kerala (India) \\ 'DYenepoya Medical College, Mangalore, Karnataka (India)
}

\section{ABSTRACT}

Background: A palpable breast lump is a common problem encountered by both the general practitioner and the surgeon. FNAC is a rapid, simple, efficient and safe method for diagnosis of palpable breast lumps. It is very useful as a pre-operative diagnostic tool.The study was carried out to diagnose palpable lumps by cytology and to confirm them with histopathologic study wherever possible. Taking histopathology as the gold standard, the sensitivity, specificity and diagnostic accuracy of FNAC in all cases diagnosed as malignant by cytology were obtained.

Methods: FNAC was performed in all patients who presented with a palpable breast lump \& the cytological findings were recorded. Subsequent histopathologic study was done wherever possible on all cases reported as malignant or suspicious for malignancyon cytology.

Result: Acorrelation of $97.67 \%$ was obtained inmalignant lesions of the breast. Sensitivity was $100 \%$; specificity and diagnostic accuracy were $97.67 \%$ each.

Conclusion: FNAC as a diagnostic modality for palpable breast lumps is a very efficient, rapid, safe and inexpensive method. In spite of its limitations, FNAC offers a high rate of sensitivity and specificity which makes it a valuable tool for the preliminary diagnosis and management of breast lumps.

Keywords: Breast Lump, Fine Needle Aspiration, Malignancy, Invasive Carcinoma

\section{Introduction}

Cancer of breast has presently overtaken cervical cancer to become the most common cancer among Indian women. From 2009 onwards, breast cancer has become the most common form of cancer in Indian women and the most common cause of cancer death in the country, accounting for more than a fifth of female cancer mortality. ${ }^{[1]}$ The incidence of breast cancer is rising and is more common among urban women compared to rural. ${ }^{[2]}$

Even though most of the breast lumps are benign, they are a source of anxiety to patients, until they undergo clinical assessment, the necessary investigations and eventual reassurance. Fine needle aspiration cytology (FNAC) of breast lumps is an accepted and established method for determining the nature of the lump, especially when it is difficult to determine the nature by clinical examination. It is a simple, cheap and rapid method, which helps in early diagnosis of breast lumps and also in planning treatment. It is proved that FNAC can reduce the number of open biopsies. ${ }^{[3]}$ In spite of its limitations, FNAC offers a high level of accuracy in diagnosis of breast lumps, by combining clinical information, radiologic studies and cytologic results. This is called "triple test process", which has to some extent, overcome the limitations of FNAC. ${ }^{[4]}$ The present study on breast FNAC was carried out to obtain cytohistopathological correlation in palpable breast lumps diagnosed as malignant by cytology and to study the accuracy of FNAC in diagnosing various malignant breast lumps.

\section{Materials and Methods}

The present study included all patients who presented with a palpable breast lump in the Surgery OPD of a tertiary care centre in South Karnataka for a period of one and a half years. History and clinical findings were recorded and procedure briefly explained to the patient, to obtain a verbal consent. FNAC was done and the cytologic features were noted in detail. The biopsy (excional/incisional) \& mastectomy specimens subsequently received were fixed in $10 \%$ formalin for 24 hours. Routine paraffin-embedded, H\&E stained sections were prepared and studied under light microscopy. The results of fine needle aspiration cytology were correlated with the histopathological diagnosis in cases diagnosed as 'malignant' and 'suspicious for malignancy' on cytology. Forty three cases, which had both FNAC and corresponding histopathology were included for 
the comparative study \& statistical analysis. Statistical analysis was used to obtain the sensitivity, specificity and diagnostic accuracy of FNAC.

\section{Result}

Out of 103 patients who underwent FNAC for palpable breast lumps, 6 were inadequate. 70 aspirates had subsequent follow-up biopsy among which 2 were suspicious for malignancy and 41 were malignant neoplasms. On subsequent histopathologic examination, 42 cases were malignant $(97.67 \%$ ) (Table). The maximum number of cases were in the age group 41-50 years (50\%). The youngest patient was 30 years old and the oldest 60 years old. Two cases were cytologically reported to be suspicious for malignancy. One case was a 48 year old patient who presented with a sub-areolar firm to hard fixed lump, measuring $5 \times 4 \mathrm{~cm}$, located in the right breast, of 1 year duration. The other patient was also aged 48 years, she presented with a firm mobile lump measuring $2 \times 2 \mathrm{~cm}$ in the lower outer quadrant of right breast since 15 days. She had history of lumpectomy twice in the same breast before, 3 years ago and 2 years ago, the details of which were not known. Cytologically, the first case showed many clusters of cells with a bimodal pattern of benign ductal cells and myoepithelial cells. A few of the clusters showed small epithelial cells with overlapping nuclei and coarse chromatin. The second case showed monolayered sheets and scattered discohesive clusters of cells with mildly pleomorphic hyperchromatic nuclei, showing nuclear overlapping in areas. Benign ductal epithelial cells arranged in monolayered sheets and bare nuclei were also seen. The first case, on lumpectomy biopsy was confirmed to be invasive lobular carcinoma, whereas the second case was benign - fibrocystic disease with atypical epithelial hyperplasia. Hence the second case turned out to be false positive. Cytologically, 36 cases were diagnosed as invasive carcinoma, 1 case as papillary carcinoma, 4 cases as invasive lobular carcinoma (Table.1). The cases which were diagnosed on cytology as invasive carcinoma were in the age group 30-58 years. The commonest age group involved was $45-54$ years. Out of the 33 cases, 2 cases had lump in both breasts and 34 cases had unilateral lumps. 18 cases involved the left breast, while 16 cases involved the right breast. Majority of the tumours were found to involve more than 1 quadrant; in most of the cases, the upper outer quadrant was invariably involved. The average size of the lump varied between $2 \times 2 \mathrm{~cm}$ and $15 \times 15 \mathrm{~cm}$.

Cytologically, the smears were highly cellular, with loosely cohesive clusters and cells with intact cytoplasm.
Nuclear pleomorphism, nuclear membrane irregularity and clumped chromatin were seen in most of the cases (Figure.1). The subsequent biopsy proved all cases except one case in the 'suspicious for malignancy' group to be malignant. Two of the cases diagnosed as invasive carcinoma showed papillary pattern and two cases showed additional features of fibrocystic change. The smears from two patients 46 years and 52 years showed loosely cohesive cell clusters and singly scattered cells. The cells were round to oval in shape, the nuclei were mildly pleomorphic and hyperchromatic. On subsequent biopsy, these cases proved to be invasive lobular carcinoma. The smears from another patient aged 48 years showed cohesive clusters of mildly pleomorphic cells with pleomorphic nuclei and prominent nucleoli, which on subsequent biopsy proved to be atypical medullary carcinoma. One case was cytologically diagnosed as papillary carcinoma in a 35 year old patient who presented with a firm, fixed lump in the upper inner quadrant of left breast, measuring $2 \times 3 \mathrm{~cm}$, of 4 months' duration. Cytologically, the smears showed papillary tissue fragments with fibrovascular stromal cores, crowded and stratified atypical columnar epithelial cells and moderate loss of cohesion (Figure. 2). The diagnosis of papillary carcinoma was confirmed on histopathology. Four cases were cytologically reported as invasive lobular carcinoma. The patients were aged 48 years, 50 years, 54 years and 60 years respectively. The sizes ranged between $4 \times 4 \mathrm{~cm}$ and $12 \times 10 \mathrm{~cm}$ and the duration, from 1 month to 5 years. The patient aged 54 years had history of mastectomy on the opposite side for carcinoma. Cytologically, the smears showed moderate cellularity, with poorly cohesive cell clusters and single files of small cells, with uniformly small nuclei with irregular shapes and indistinct cytoplasm. Histopathological examination confirmed the diagnosis in all the 4 cases.

Hence the overall cytohistologic correlation was $97.67 \%$. One case diagnosed as suspicious for malignancy on cytology, found to be benign on histopathology, was regarded as false positive. Hence sensitivity of the present study was $100 \%$ and specificity and diagnostic accuracy were $97.67 \%$.

\section{Discussion}

The aspirates were considered to be inadequate if only fat and fibrous tissue were aspirated, without any cellular material, even after repeat aspiration. Previous studies show wide variation in percentage of unsatisfactory aspirates. ${ }^{[5-7]}$ Unsatisfactory smears are said to result from: fibrotic/desmoplastic target tissue giving a scanty 
Tables: Cytohistolologic correlation in various diagnostic categories

\begin{tabular}{|c|c|c|c|c|}
\hline Cytological diagnosis & No. of cases & Percentage & Histopathologic diagnosis & No. of cases \\
\hline \multirow[t]{2}{*}{ Suspicious for malignancy } & \multirow[t]{2}{*}{2} & \multirow[t]{2}{*}{4.65} & Invasive lobular $\mathrm{Ca}$ & 1 \\
\hline & & & $\begin{array}{l}\text { Fibrocystic disease with atypical epithelial } \\
\text { hyperplasia (FP) }\end{array}$ & 1 \\
\hline \multirow[t]{5}{*}{ Invasive $\mathrm{Ca}$} & \multirow[t]{5}{*}{36} & \multirow[t]{5}{*}{83.72} & Invasive Ca NOS & 28 \\
\hline & & & Invasive lobular $\mathrm{Ca}$ & 2 \\
\hline & & & Medullary Ca & 3 \\
\hline & & & Atypical medullary $\mathrm{Ca}$ & 2 \\
\hline & & & $\begin{array}{l}\text { Paget's disease of breast with metastatic } \\
\text { deposits from invasive carcinoma in axillary } \\
\text { lymph nodes }\end{array}$ & 1 \\
\hline Papillary $\mathrm{Ca}$ & 1 & 2.32 & Papillary $\mathrm{Ca}$ & 1 \\
\hline ILC & 4 & 9.30 & Invasive lobular $\mathrm{Ca}$ & 4 \\
\hline Total & 43 & 100 & & 43 \\
\hline
\end{tabular}

(NOS - not otherwise specified, ILC - Invasive lobular carcinoma, Ca - carcinoma, FP - False positive)

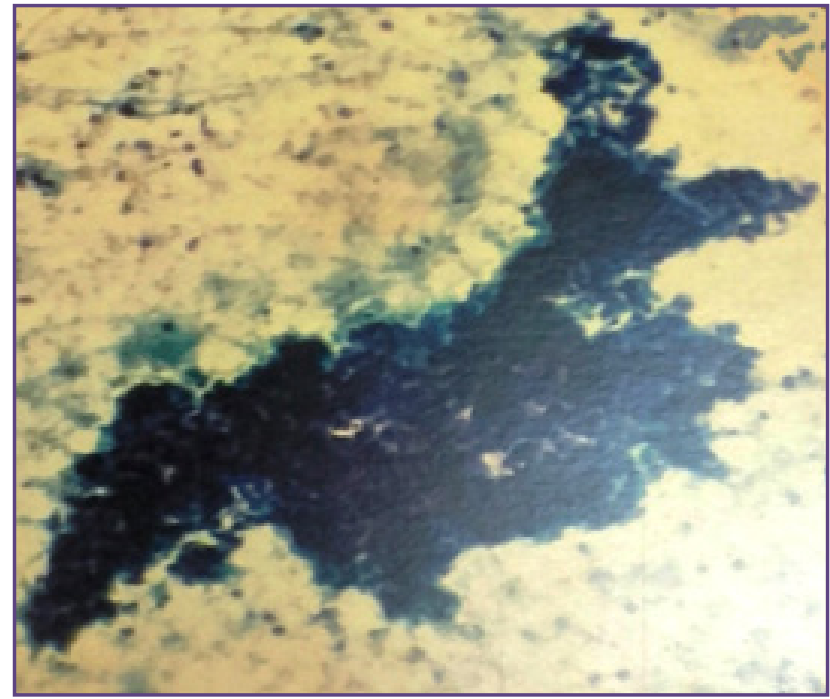

Fig. 1: Invasive carcinoma, NOS FNAC (10x). Showing high cellualarity, with loosely cohesive clusters of cells showing nuclear pleomorphism \& clumped chromatin.

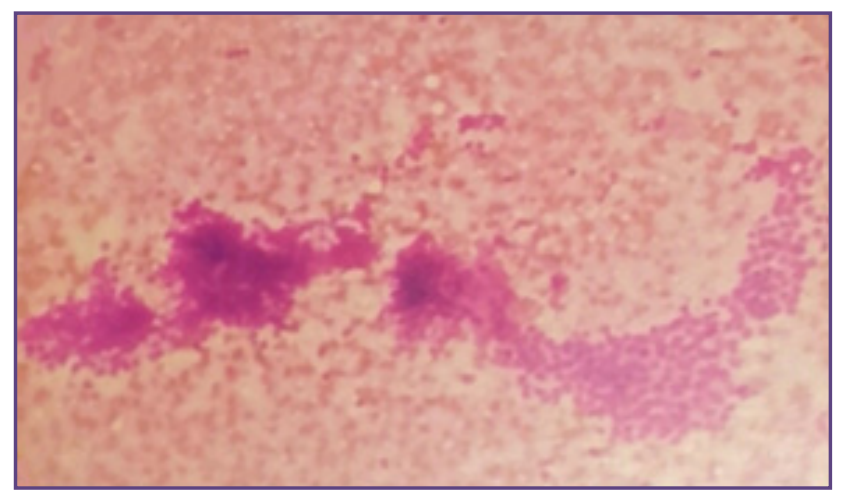

Fig. 2: Papillary carcinoma FNAC (20x). Shows papillary tissue fragments with fibrovasular cores, with crowding \& stratification of epithelial cells showing atypia

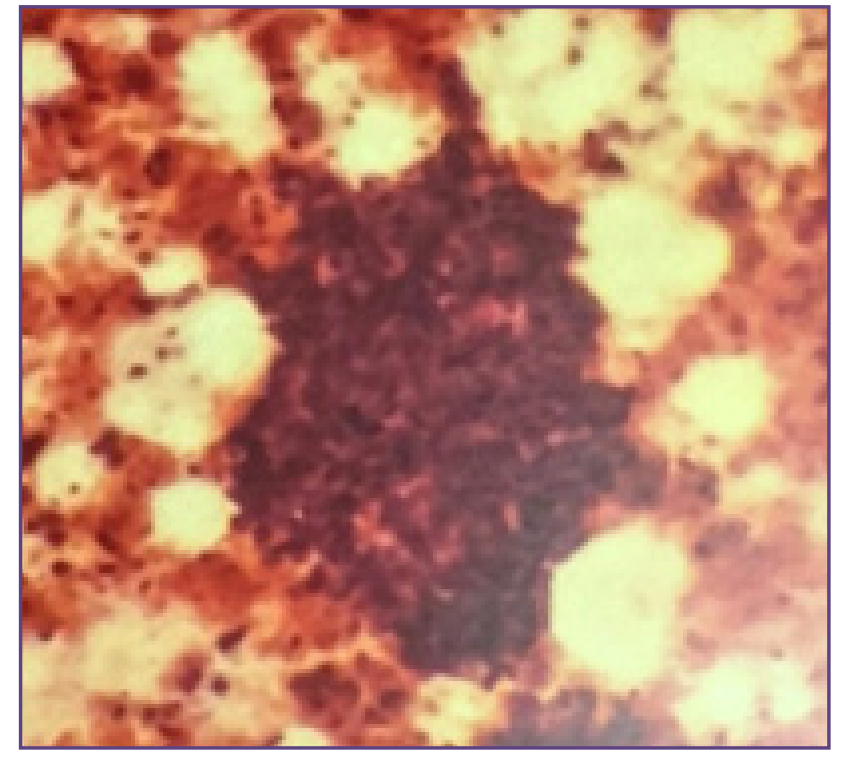

Fig. 3: Medullary carcinoma FNAC (40x). Showing loosely cohesive pleomorphic ductal epithelial cells.

yield; needle in central cystic/necrotic/hemorrhagic area, devoid of diagnostic cells; needle in a dominant benign mass, missing a small adjacent malignant lesion and when needle has missed the target tangentially. ${ }^{[8]}$ Out of the two cases diagnosed as suspicious for malignancy, one case turned out to be benign (false positive) on subsequent histopathologic examination. Both these cases on cytology showed some atypical features which led to the diagnosis of suspicious for malignancy. The false positive report on FNAC was due to drying artefact. Also, artefacts like crush artefacts on air dried smears, drying artefacts on alcohol fixed smears may cause nuclei of benign epithelial cells to look larger and irregular so that they could be mistaken for malignant cells. One should therefore disregard those 
parts of the smear in which fixation and cell preservation is poor. ${ }^{[8]}$ Cytologically, one case showed many clusters of cells with a bimodal pattern of benign ductal cells and myoepithelial cells, a few of the clusters showing small epithelial cells with overlapping nuclei and coarse chromatin. The other case showed monolayered sheets and scattered discohesive clusters of cells with mildly pleomorphic hyperchromatic nuclei, showing nuclear overlapping in areas. Presence of uniformly enlarged nuclei with prominent nucleoli, occasional marked nuclear enlargement and moderate pleomorphism are seen in benign lesions like fibrocystic disease or fibroadenoma, leading to false positive results. ${ }^{[9]}$

In the true false negative cases, the denominators are poor sampling technique, mislocalization of the tumor, or the presence of a well-defined tumor demonstrating minimal atypia. The widespread adoption of breast screening and advances in imaging techniques also resulted in the detection of small lesions, and understandably, FNAC of these small lesions has a significant risk of missing these lesions, leading to potentially false-negative result ${ }^{[10]}$

The useful parameters to predict malignancy in FNAC breast are high nuclear: cytoplasmic ratio, epithelial cell atypia, low number of bipolar nuclei and necrosis. ${ }^{[12]}$ Diagnosing gray zone pathology as atypical, in FNAC, causes no delay in treatment, as excisional biopsy is recommended for all equivocal cases. ${ }^{[12]}$ Thirty six cases were diagnosed as invasive carcinoma on cytology. Cytological smears from these cases were highly cellular, showing loosely cohesive clusters of pleomorphic epithelial cells and single cells with intact cytoplasm. The reliable cytological features of invasion are fat infiltration, fibroblast proliferation, elastoid stromal fragments, stromal invasion, tubule formation by tumor cells, intracytoplasmic lumina formation and the presence of lymphocytes around the tumor cells. ${ }^{[13]}$

According to the study by Young, et al., the highest rate of correct diagnosis on FNAC was seen in invasive ductal carcinoma $(65 \%){ }^{[14]}$

Cytologically, as noted by Young, et al., medullary carcinomas are typically cellular and composed of large tumor cells, either isolated or in loose syncitia, with a small nuclear-cytoplasmic ratio. ${ }^{[14]}$ According to Jan F. Silverman, numerous admixed lymphocytes and some plasma cells are frequently present, in aspirates from medullary carcinoma. In any aspirate of a breast mass demonstrating lymphoid cells, a diligent search for malignant epithelial cells should be made to avoid a false negative diagnosis. ${ }^{[15]}$
In the present study, the cases diagnosed as medullary carcinoma by histopathology failed to show the typical cytologic features and showed only loosely cohesive pleomorphic ductal epithelial cells and was thus diagnosed only as invasive carcinoma (Fig. 3).

Cytologically, the smears from papillary carcinoma showed papillary tissue fragments with fibrovascular stromal cores, crowded and stratified atypical columnar epithelial cells and moderate loss of cohesion.

Similar features were noticed by Gomez-Aracil et al, who noticed abundance of cellular material, three-dimensional papillary clusters without fibrovascular connective tissue cores, small papillae arranged in cell balls, tall columnar cells and isolated naked nuclei and numerous haemosiderinladen macrophages in papillary carcinomas. ${ }^{[16]}$

According to Prathibha D et. al, although three-dimensional clusters on cytosmears had a high specificity for recognizing papillary lesions, pseudopapillary structures are found in fibroadenoma and invasive ductal carcinoma NOS. Immunohistochemistry for smooth muscle actin was found to be useful in identifying the myoepithelial cells, pointing towards a benign nature. ${ }^{[17]}$ Cytological diagnosis of papillary lesions shows a significant error rate $(17 \%)$ with overlapping features like cell balls, background single cells, papillary clusters. Cellular atypia and fragments with long and slender papillae with ramifying edges favour papillary carcinoma. ${ }^{[18]}$

The 2 cases diagnosed on histopathology as medullary carcinoma were diagnosed on cytology as invasive carcinoma. Both cases on histopathology showed syncitial sheets of highly pleomorphic cells with pleomorphic nuclei and high mitotic rate. Lymphocytic infitrate was sparse and seen only at the border of the tumor. So the histopathological diagnosis was given as atypical medullary carcinoma.

Rajesh L et.al have found that FNAC smears of ILC showed moderate to abundant cellularity, with . cells arranged both in clusters and in dissociation. Individual cells were monomorphic to mildly pleomorphic and the cells were smaller with a smooth, regular nuclear margin, bland chromatin and indistinct nucleoli. Indian file arrangement was frequently observed. Nuclear molding and intranuclear inclusions were also noted. Intracytoplasmic lumina were seen in occasional cases. ${ }^{[19]}$

The shape of the nuclei was rather characteristic, with irregular angular, triangular, indented, and occasionally budding nuclei. Carcinomas with high nuclear grade corresponded mainly to variants of lobular carcinoma and 
especially to the pleomorphic type the cytologic diagnosis of malignancy is more difficult in lobular carcinoma than in ductal carcinoma, even in the hands of experienced cytopathologists. ${ }^{[20]}$

In the present study, the smears of lobular carcinoma showed moderate cellularity, with poorly cohesive cell clusters, single files, uniformly small nuclei with irregular shapes and indistinct cytoplasm. The diagnosis of lobular carcinoma was confirmed subsequently on histopathology.

There are known pitfalls in identification of invasive lobular carcinoma on FNAB. The cell size, cellularity, cell uniformity and chromatin pattern help to distinguish lobular carcinomas from benign lesions; cellularity and nuclear margin irregularities are the key features which help to distinguish them from invasive carcinoma, NOS. ${ }^{[20]}$

Out of the 42 cases diagnosed as malignant (including suspicious category) on cytology, there was one false positive case and subtyping was accurate in 34 cases ( $81 \%)$.

Hence accuracy of subtyping on FNAC was highest for invasive carcinoma (100\%). This was similar to the finding of Young et al. Hundred percent accuracy obtained in papillary carcinoma may be disregarded as the sample size is too small. Lobular carcinoma showed intermediate accuracy (66.7\%). Lowest rate of accuracy in subtyping was noted in medullary carcinoma and atypical medullary carcinoma, similar to the findings of Young et al. ${ }^{[14]}$

\section{Conclusion}

Fine needle aspiration cytology as a diagnostic procedure in case of breast lumps is a very efficient, safe and inexpensive method. It gives rapid diagnoses with minimal discomfort to the patient. Also, the rate of complications is very low.

Even though few limitations do exist, the results of FNAC possess high levels of sensitivity and specificity in the hands of an experienced cytopathologist. It acts as an extremely useful adjunct to histopathology and should be considered as the first line of management for all palpable breast lumps.

\section{Reference}

1. Ferlay J, Soerjomataram I, Ervik M, et al. GLOBOCAN 2012 v1.0, Cancer Incidence and Mortality Worldwide: IARC Cancer Base No. 11. Lyon, France: International Agency for Research on Cancer, 2013. http://globocan.iarc.fr
2. Nagrani RT, Budukh A, Koyande S, Panse NS, Mhatre SS, Badwe R. Rural urban differences in breast cancer in India. Indian J Cancer 2014;51:27781

3. Mulazim HB, Madiha A, Shahid J, et al. Use of Fine-Needle Aspiration in the Evaluation of Breast Lumps. Pathology Research International, vol. 2011, Article ID 689521.

4. Kharkwal S, Sameer, Mukherjee A. Triple test in carcinoma breast. J Clin Diagn Res. 2014; 8(10):NC09-11.

5. Yu Y-H, Wei W, Liu J-L. Diagnostic value of fine-needle aspiration biopsy for breast mass: a systematic review and meta-analysis. BMC Cancer 2012;12:41.

6. Kanchanabat B, Kanchanapitak P, Thanapongsathorn W, Manomaiphiboon A. Fine-needle aspiration cytology for diagnosis and management of palpable breast mass. Aust NZ J Surg. 2000;70:791-794.

7. Kaur G, Sivakumar S . Comparison of unsatisfactory aspirates in fine needle aspiration performed by surgical medical officers and pathologists. Journal of Cytology, Vol. 24, No. 2, April-June, 2007, pp. 82-84

8. Svante R Orell, Gregory F Sterrett, Darrel Whitaker, Philippe Vielh. Techniques of FNA Cytology. In Svante R Orell, Gregory F Sterrett, Darrel Whitaker. Fine Needle Aspiration Cytology. $5^{\text {th }}$ ed. New Delhi: Elsevier India Pvt. Ltd, 2011, Page No. 8-27.

9. Mulazim HB, Madiha A, Shahid J, Shahida N, Bashir S, Irfan M. Bakhshi,nd Shaharyar. Use of Fine-Needle Aspiration in the Evaluation of Breast Lumps. Pathology Research International Volume 2011, Article ID 68952.

10. Paulo M, Maribel L, Puay-Hoon Tan, and Gary M. Tse. Fine Needle Aspiration Cytology of the Breast: The Nonmalignant Categories, Pathology Research International, vol. 2011, Article ID 547580.

11. Phuong Viet The Tran, Philip C. W. Lui, Alex M. C. Yu, Pham The Vinh, Helen H. L. Chau, Tony K. F. Ma, PuayHoon Tan, Gary M. Tse. Atypia in fine needle aspirates of breast lesions. J Clin Pathol 2010. 63:585-591.

12. Ozkara SK, Ustun MO, Paksoy N. The gray zone in breast fine needle aspiration cytology. How to report on it? Acta Cytol 2002 May-Jun. 46(3):513-8.

13. Mitra S, Dey P. Grey zone lesions of breast: Potential areas of error in cytology. Journal of Cytology / Indian Academy of Cytologists 2015. 32(3):145-152.

14. Young, Nancy A, et al. Diagnosis and subclassification of breast carcinoma by fine-needle aspiration biopsy: results of interlaboratory comparison program in non-gynaecologic cytopathology. Arch Pathol Lab Med 2002; 126: 1453-1457.

15. Jan F. Silverman. Breast. In: Marluce Bibbo. Comprehensive Cytopathology. $4^{\text {th }}$ ed. Philadelphia: W. B. Saunders company, 2014.

16. Gomez-Aracil V, Mayayo E, Azua J, Arraiza A. Papillary neoplasms of the breast: clues in fine needle aspiration cytology. Cytopathology 2002, 13: 22-30 
17. Prathiba D, Rao S, Kshitija K, Joseph LD. Papillary lesions of breast - An introspect of cytomorphological features. J Cytol. 2010, 27(1):12-5.

18. Tse GM, Ma TK, Lui PC, Ng DC, Yu AM, Vong JS, Niu Y, Chaiwun B, Lam WW, Tan PH. Fine needle aspiration cytology of papillary lesions of the breast: how accurate is the diagnosis? J Clin Pathol. 2008 Aug; 61(8):945-9.
19. Rajesh L, Dey P, Joshi K. Fine needle aspiration cytology of lobular breast carcinoma. Comparison with other breast lesions. Acta Cytol 2003, 47(2):177-82.

20. Menet E, Becette V, Briffod M. Cytologic diagnosis of lobular carcinoma of the breast: experience with 555 patients in the Rene Huguenin Cancer Center. Cancer. 2008;114(2):111-117.

*Corresponding author:

Dr. C. Hazeena, 'Sushara', Kunhipally, Kottali (P.O), Kannur - 670005, Kerala, India

Phone: +91 9061027799

Email: hazeenac@gmail.com

Date of Submission : 26.08.2017

Date of Acceptance : 24.10.2017

Financial or other Competing Interests: None.

Date of Publication : 28.01.2018 